\title{
Preparation, characterization of a ceria loaded carbon nanotubes nanocomposites photocatalyst and degradation of azo dye Acid Orange 7
}

\author{
Wen Tao, Tang Yu-bin*, Chen Fang-yan, Mo Bing-yu \\ Jiangsu University of Science and Technology, China \\ School of Environmental and Chemical Engineering \\ *Corresponding author's e-mail: tangyubin@just.edu.cn; ybbill@163.com
}

\begin{abstract}
Keywords: Carbon nanotubes, ceria, nanocomposites photocatalyst, preparation, acid orange 7 .
Abstract: A ceria loaded carbon nanotubes $\left(\mathrm{CeO}_{2} / \mathrm{CNTs}\right)$ nanocomposites photocatalyst was prepared by chemical precipitation, and the preparation conditions were optimized using an orthogonal experiment method. HR-TEM, XRD, UV-Vis/DRS, TGA and XPS were used to characterize the photocatalyst. Nitrogen adsorption-desorption was employed to determine the BET specific surface area. The results indicated that the photocatalyst has no obvious impurities. $\mathrm{CeO}_{2}$ was dispersed on the carbon nanotubes with a good loading effect and high loading efficiency without agglomeration. The catalyst exhibits a strong ability to absorb light in the ultraviolet region and some ability to absorb light in the visible light region. The $\mathrm{CeO}_{2} / \mathrm{CNTs}$ nanocomposites photocatalyst was used to degrade azo dye Acid Orange $7(40 \mathrm{mg} / \mathrm{L})$. The optical decolorization rate was $66.58 \%$ after xenon lamp irradiation for $4 \mathrm{~h}$, which is better than that of commercial $\mathrm{CeO}_{2}(43.13 \%)$. The results suggested that $\mathrm{CeO}_{2}$ loading on $\mathrm{CNTs}$ not only enhanced the optical decolorization rate but also accelerated the separation of $\mathrm{CeO}_{2} / \mathrm{CNTS}_{2}$ and water.
\end{abstract}

\section{Introduction}

Ceria $\left(\mathrm{CeO}_{2}\right)$ is one of the rare earth oxides that has widely been used in the water gas shift reaction (Rodriguez et al. 2007, Vindigni et al. 2011), automotive three-way catalytic converters (Matsumoto 2004), green phosphors (Long et al. 2006), oxygen storage material (Campbell et al. 2005, Esch et al. 2005), solid fuel cells (Park et al. 2000) and antioxidants in biological model systems (Karakoti et al. 2010, Singh et al. 2011) due to its unique cubic fluorite structure (Trovarelli 2002), oxygen storage capacity (Walton 2011) and high activity.

The photocatalytic oxidation performance of ceria is the focus of research due to its relatively numerous oxygen vacancies and low redox potential (Zhang et al. 2010). Zhai et al. (Zhai et al. 2007) employed homemade $\mathrm{CeO}_{2}$ nanocrystals as a catalyst for the degradation of $10 \mathrm{mg} / \mathrm{L}$ of acid black dye in water in sunlight, and the decolorization rate was 97\%. Ji et al. (Ji et al. 2009) and Feng et al. (Feng et al. 2013) used $\mathrm{CeO}_{2}$ as a photocatalyst to degrade acid orange II, and its photocatalytic ability was better than that of commercial $\mathrm{TiO}_{2}(\mathrm{P} 25)$. Because ceria exhibits excellent photocatalytic performance, it is used as a support for loading other catalysts or as the main photocatalyst when it is loaded on other materials. The ability to load nanosized ceria particles on catalyst supports that have a high specific surface area and stability is required (Guerrero-Ruiz 1994, Soria et al. 1996, Trovarelli et al. 1995).

Because carbon nanotubes have a large specific surface area and specific catalytic property as well as due to the advances in nanotube-walls functionalized research, much interest has been focused on CNTs for use in catalytic chemistry since their discovery in 1991 (Iijima 1991). CNTs exhibit high thermal and chemical stability due to their cylindrical layered, hollow tube nanostructures, which allows them to act as a catalysts to prepare loaded nanometals and metal oxide particles (Peng et al. 2005, Planeix et al. 1994). Researchers from the Chemistry Institute of Chinese Academy of Sciences used CNTs as a support for loading rare earth oxide to prepare $\mathrm{CNTs}-\mathrm{Eu}_{2} \mathrm{O}_{3}$ one-dimensional composite catalysts in 2004 (Fu et al. 2004). Kang et al. (Kang et al. 2005) loaded platinum on CNTs to enhance the structural stability and electronic property of the CNTs. In addition, Rao et al. (Rao et al. 2012) prepared a $\mathrm{CeO}_{2} / \mathrm{CNTs}$ composite catalyst to dehydrogenate and oxidize ethylbenzene to styrene in a carbon dioxide atmosphere. Peng et al. (Peng et al. 2005) utilized $\mathrm{CeO}_{2}$ loaded with CNTs to remove arsenate in water.

However, for the degradation of dye wastewater, researchers only used either $\mathrm{CeO}_{2}$ as a photocatalyst (Chen et al. 2011, Pouretedal et al .2010) or CNTs as an adsorbent to adsorb pollutants after pretreatment (Gao et al. 2013, Mishra et al. 2010). The use of $\mathrm{CeO}_{2} / \mathrm{CNTs}$ nanocomposites materials as photocatalysts for the degradation of azo dyes has not been reported. $\mathrm{CeO}_{2}$ nanoparticles and $\mathrm{CNTs}$ are both suspended in water, which makes their separation from water difficult. The decolorization efficiency of azo dye wastewater using $\mathrm{CeO}_{2}$ nanoparticles or CNTs is limited. In this paper, we loaded $\mathrm{CeO}_{2}$ on CNTs to prepare a nanocomposites catalyst that is 
easily separated from water and exhibits good decolorization performance to provide a new photocatalyst for the degradation of azo dyes.

\section{Materials and methods}

Various reagents employed [commercial $\mathrm{CeO}_{2}, \mathrm{CeCl}_{3} \cdot 7 \mathrm{H}_{2} \mathrm{O}$, $\mathrm{NaOH}$, polyethylene glycol (PEG 600), ethanol and a concentrated $\mathrm{HNO}_{3}$ aqueous solution] were purchased from Sinopharm Chemical Reagent Co., Ltd. in $99.99 \%$ purity or greater. Multi-walled carbon nanotubes with an average tube diameter of $80 \mathrm{~nm}$ and an average tube length of $20 \mu \mathrm{m}$ were purchased from Nanjing Xianfeng Co., Ltd. Deionized water was used to prepare the solvent and wash sample in this research.

\section{Preparation of nanocomposites photocatalyst}

Pretreatment of carbon nanotubes: $1 \mathrm{~g}$ of raw CNTs was weighed into a three-necked flask (250 mL capacity), and $100 \mathrm{~mL}$ of a concentrated $\mathrm{HNO}_{3}$ aqueous solution with a volume fraction of $65 \% \sim 68 \%$ was added to the three-necked flask to treat the raw CNTs prior to purification. Then, the mixture was refluxed for $3 \mathrm{~h}$ at $125^{\circ} \mathrm{C}$. Next, the mixture was successively washed with ethanol at first, then washed with deionized water until $\mathrm{pH}$ of 7 was obtained, and afterwards it was cooled to room temperature. Finally, the mixture was placed into a blast oven to dry for $24 \mathrm{~h}$ at $60^{\circ} \mathrm{C}$ and then ground prior to storage.

Preparation of nanocomposites photocatalyst: A known quantity of pretreated carbon nanotubes was mixed with a known quantity of deionized water and then ultrasonically dispersed for $10 \mathrm{~min}$. After adequately stirring for $1 \mathrm{~h}$, a known quantity of $\mathrm{CeCl}_{3} \cdot 7 \mathrm{H}_{2} \mathrm{O}$ with a mass ratio of $\mathrm{Ce}$ to $\mathrm{C}$ of $2: 3,1: 1$, 4:3 or 3:2 and PEG 600 with a ratio of polyethylene glycol mass to the total mass of carbon nanotubes and $\mathrm{CeCl}_{3} \cdot 7 \mathrm{H}_{2} \mathrm{O}$ of $1 \%$ was added. $\mathrm{A} \mathrm{NaOH}$ aqueous solution $(6 \mathrm{~g} / \mathrm{L})$ was slowly added dropwise until the $\mathrm{pH}$ reached 11.0, 11.5, 12.0 or 12.5, followed by continuous stirring for $1 \mathrm{~h}, 2 \mathrm{~h}, 3 \mathrm{~h}$ or $4 \mathrm{~h}$, respectively, at room temperature. Then, the mixture was filtered and washed until neutral and dry, which yielded a loose black powder.

Finally, the black powder was dried and placed in a pipe furnace prior to being heated at a heating rate of $5^{\circ} \mathrm{C} / \mathrm{min}$ to $400,410,420$ or $430^{\circ} \mathrm{C}$ in air and maintained for $5 \mathrm{~min}$, $10 \mathrm{~min}, 15 \mathrm{~min}$ or $20 \mathrm{~min}$, respectively. Then, the $\mathrm{CeO}_{2} / \mathrm{CNTs}$ nanocomposites photocatalyst was obtained.

\section{Characterization of nanocomposites photocatalyst}

The morphological features and approximate size of the sample were observed using a Tecnai 12 transmission electron microscope (TEM) made by the Philips Company (Netherlands) and a FEI Tecnai G2 F30 S-Twin 300 KV high-resolution field emission transmission electron microscope (HR-TEM). The crystalline microstructure and phase composition of the sample were evaluated using German Bruker-AXS D8 Advance X-ray diffractometer (XRD), and test conditions were as follows: $\mathrm{Cu}$ target, diffuse radiation, tube voltage of $40 \mathrm{kV}$, tube current of $30 \mathrm{~mA}$, scanning speed of $2 \mathrm{deg} / \mathrm{min}$, scan range $2 \theta$ of $20^{\circ}$ $\sim 80^{\circ}$, and slit width of $0.3 \mathrm{~mm}$. The thermal weight loss of the sample during calcination was determined using an American Perkin Elmer Diamond TGA analyzer in air (TGA) at a heating rate of $5^{\circ} \mathrm{C} / \mathrm{min}$ over a temperature range of $100 \sim 700^{\circ} \mathrm{C}$. The absorbance threshold of the sample was recorded by a Japanese Shimadzu UV3600 UV-visible spectrophotometer (UV-Vis/DRS) with a scanning wavelength of 200 800 nm. The specific surface area of the sample was calculated using an American Micromeritics ASAP2020 M+C physical adsorption instrument. X-ray photoelectron spectroscopy (XPS) was performed to identify elements and analyze the valence of the elements in the samples using a Japanese ULVAC-PHT PHI 500 VersaProbe X-ray photoelectron spectrometer with a binding energy range of $0 \sim 1000 \mathrm{eV}$.

\section{Photocatalytic degradation experiment}

In a typical photocatalytic degradation experiments, $20 \mathrm{~mL}$ of Acid Orange 7 aqueous solution of $40 \mathrm{mg} / \mathrm{L}$ initial concentration was added to a test tube, then, the $\mathrm{pH}$ was adjusted to 5.0. And then, $10 \mathrm{mg}$ of the $\mathrm{CeO}_{2} / \mathrm{CNTs}$ nanocomposites photocatalyst was introduced into the test tube and was dispersed by ultrasonic for $5 \mathrm{~min}$. The test tube was then agitated for $1 \mathrm{~h}$ in the dark to reach adsorption-desorption equilibrium.

Then, a $500 \mathrm{~W}$ xenon lamp was used as the simulated solar light source to irradiate the suspension for $4 \mathrm{~h}$ at a distance of $8 \mathrm{~cm}$ under uniform stirring. Finally, the absorbance of the supernatant was measured with a visible spectrophotometer at a wavelength of $484 \mathrm{~nm}$ to examine the optical decolorizing property of the $\mathrm{CeO}_{2} / \mathrm{CNTs}$ nanocomposites photocatalyst after being filtered by a microporous membrane $(0.22 \mu \mathrm{m})$.

\section{Settling performance experiment}

The settling performance of the $\mathrm{CeO}_{2} / \mathrm{CNTs}$, commercial $\mathrm{CeO}_{2}$ and raw CNTs was tested using an ideal static settling experiment. In a typical settling performance experiment, the suspended particles were evenly dispersed in deionized water and then injected into a settling column. The particles were sampled at the same height, $\mathrm{H}$, of the settling column (starting from the bottom of the settling column, $\mathrm{H}$ is $10 \mathrm{~cm}$ ), at different times, $t$, followed by measuring the particulate matter concentration, C. Finally, the sedimentation curves were depicted as plots of the concentration ratio, $\mathrm{C} / \mathrm{C}_{0}\left(\mathrm{C}_{0}\right.$ represents initial concentration of particulate matter), as a function of the corresponding settling velocity, $u(=\mathrm{H} / \mathrm{t})$. Therefore, the total removal of the suspended particles at a known settling velocity was calculated from the plots.

\section{Results and discussion}

\section{Results and analysis of the orthogonal test}

The stirring reaction time, cerium carbon ratio, $\mathrm{pH}$, calcination temperature and holding time were investigated in this study, and the optical decolorization rate of Acid Orange 7 as evaluation index based on single factor experiments (data not shown) and designed orthogonal test program of five factors and four levels were used to determine the optimum parameters for the preparation of the $\mathrm{CeO}_{2} / \mathrm{CNTs}$ nanocomposites photocatalyst. The results and analysis of the orthogonal test for the preparation of $\mathrm{CeO}_{2} / \mathrm{CNTs}$ nanocomposites photocatalyst are reported in Tables 1 and 2 .

As shown in Table 1, the test results indicated that the highest rate of optical decolorization was observed for No. 11 (62.14\%). However, No. 11 may not be the optimal choice. Therefore, further analysis is required.

Level difference analysis was used to investigate the level changes of the various factors that impact the tested items. 
When the level difference $(\mathrm{R})$ is larger, there is a greater impact on the factors that vary within a target range for testing indicator values, and the correct factor is the one with the primary influence. The results in Table 2 indicate that the level difference of the calcination temperature is the largest (21.777), which indicated that it has the largest influence on the preparation. Similarly, the level difference for the $\mathrm{pH}$ is the smallest (3.947), which indicated that the $\mathrm{pH}$ has the smallest effect on the preparation. Therefore, the order of effect of each factor on the photodecolorization rate from largest to smallest is as follows: calcination temperature $>$ holding time $>$ stirring reaction time $>$ cerium carbon ratio $>\mathrm{pH}$.

We determined the theoretical optimal solution (Group A) based on the largest mean value of each factor (i.e., stirring reaction time of $4 \mathrm{~h}$, cerium carbon ratio of $4: 3, \mathrm{pH}$ of 11.5 , calcination temperature of $410^{\circ} \mathrm{C}$ and holding time of $5 \mathrm{~min}$ ).

The choice of the optimal scheme requires a comprehensive analysis and verification test. The preceding analysis indicated that the optimum parameters for the preparation of the $\mathrm{CeO}_{2} / \mathrm{CNTs}$ nanocomposites photocatalyst include either "No. 11 " or Group A. However, the best choice will need to be determined through further testing.
This verification experiment was repeated twice for each of the two schemes mentioned above, and the results indicated that the optical decolorization rates of No. 11 were $62.15 \%$ and $61.26 \%$. In addition, the optical decolorization rates for Group A were $66.58 \%$ and $68.13 \%$. Obviously, the optical decolorization rates of Group A are still higher than those of No. 11. Therefore, the optimized conditions for the preparation of the $\mathrm{CeO}_{2} / \mathrm{CNTs}$ nanocomposites photocatalyst are as follows: stirring reaction time of $4 \mathrm{~h}$, cerium carbon ratio of $4: 3, \mathrm{pH}$ of 11.5 , calcination temperature of $410^{\circ} \mathrm{C}$ and holding time of $5 \mathrm{~min}$. These conditions are used to prepare the photocatalysts employed in the rest of the experiments.

\section{Characterization of the nanocomposites photocatalyst \\ TEM/HRTEM}

Fig. 1 shows the TEM and HR-TEM images of raw CNTs and the $\mathrm{CeO}_{2} / \mathrm{CNTs}$ nanocomposites photocatalyst. As shown in Fig. 1a (and inset), the tube-body of the CNTs is clean and well distributed after pretreatment. The TEM images of the $\mathrm{CeO}_{2} / \mathrm{CNTs}$ nanocomposites photocatalyst are shown in Fig. $1 \mathrm{~b}$ (and inset), which indicates that the diameter of the CNTs were

Table 1. Results from the orthogonal testt

\begin{tabular}{|c|c|c|c|c|c|c|}
\hline No. & A & B & C & D & E & Photodecolorization rate (\%) \\
\hline 1 & 1 & $2: 3$ & 11.0 & 400 & 5 & 51.73 \\
\hline 2 & 1 & $1: 1$ & 11.5 & 410 & 10 & 52.32 \\
\hline 3 & 1 & $4: 3$ & 12.0 & 420 & 15 & 23.67 \\
\hline 4 & 1 & $3: 2$ & 12.5 & 430 & 20 & 22.41 \\
\hline 5 & 2 & $2: 3$ & 11.5 & 420 & 20 & 24.82 \\
\hline 6 & 2 & $1: 1$ & 11.0 & 430 & 15 & 54.13 \\
\hline 7 & 2 & $4: 3$ & 12.5 & 400 & 10 & 57.10 \\
\hline 8 & 2 & $3: 2$ & 12.0 & 410 & 5 & 39.96 \\
\hline 9 & 3 & $2: 3$ & 12.0 & 430 & 10 & 41.82 \\
\hline 10 & 3 & $1: 1$ & 12.5 & 420 & 5 & 62.14 \\
\hline 11 & 3 & $4: 3$ & 11.0 & 410 & 20 & 53.26 \\
\hline 12 & 3 & $3: 2$ & 11.5 & 400 & 15 & 48.85 \\
\hline 13 & 4 & $2: 3$ & 12.5 & 410 & 15 & 54.94 \\
\hline 14 & 4 & $1: 1$ & 12.0 & 400 & 20 & 52.60 \\
\hline 15 & 4 & $4: 3$ & 11.5 & 430 & 5 & 42.99 \\
\hline 16 & 4 & $3: 2$ & 11.0 & 420 & 10 & \\
\hline
\end{tabular}

A: stirring reaction time $(\mathrm{h})$; $\mathrm{B}$ : cerium carbon ratio; $\mathrm{C}$ : $\mathrm{pH}$; $\mathrm{D}$ : calcination temperature $\left({ }^{\circ}\right)$; $\mathrm{E}$ : holding time $(\min )$.

Table 2. Analysis of the results from the orthogonal test

\begin{tabular}{|c|c|c|c|c|c|}
\hline Levels & A & B & C & D & E \\
\hline $\mathrm{k}_{1}$ & 37.532 & 41.340 & 45.305 & 53.515 & 50.813 \\
\hline $\mathrm{k}_{2}$ & 40.102 & 43.360 & 45.750 & 55.102 & 47.350 \\
\hline $\mathrm{k}_{3}$ & 49.295 & 48.135 & 43.918 & 33.325 & 37.535 \\
\hline $\mathrm{k}_{4}$ & 49.845 & 43.940 & 41.803 & 34.832 & 41.078 \\
\hline $\mathrm{R}$ & 12.313 & 6.795 & 3.947 & 21.777 & 13.278 \\
\hline
\end{tabular}

A: stirring reaction time $(\mathrm{h})$; $\mathrm{B}$ : cerium carbon ratio; $\mathrm{C}$ : $\mathrm{pH}$; $\mathrm{D}$ : calcination temperature $\left({ }^{\circ}\right)$; $\mathrm{E}$ : holding time $(\min )$. 

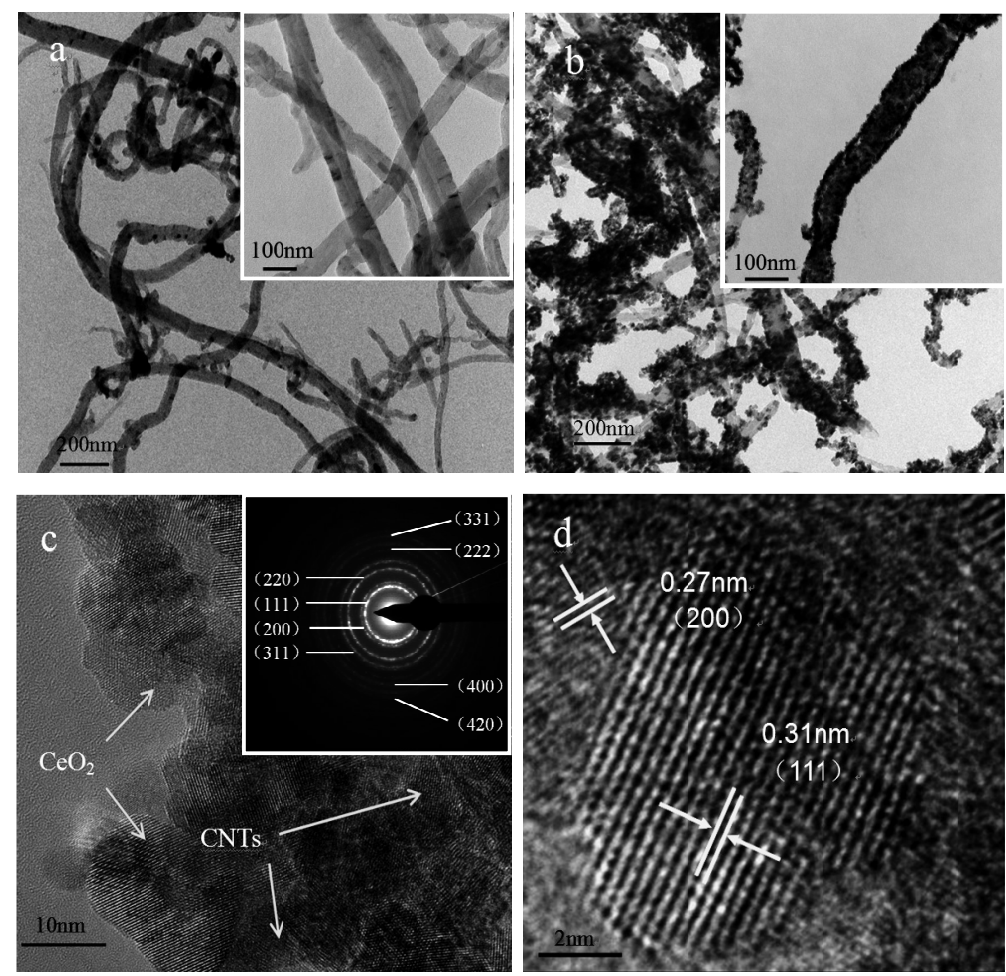

Fig. 1. TEM images of raw CNTs (a), $\mathrm{CeO}_{2} / \mathrm{CNTs}(\mathrm{b})$, HRTEM images of $\mathrm{CeO}_{2} / C N T s$ (c\&d) and SAED pattern of $\mathrm{CeO}_{2} / \mathrm{CNTs}$ (c, inset)

significantly thicker after loading. In addition, the $\mathrm{CeO}_{2}$ particles are uniformly loaded without agglomeration, which indicates that the product has a high loading efficiency. As shown in the HRTEM images of the $\mathrm{CeO}_{2} / \mathrm{CNTs}$ nanocomposites photocatalyst in Fig. $1 \mathrm{c}$, the $\mathrm{CeO}_{2}$ particles are loaded on the CNTs. In addition, the diameter of the $\mathrm{CeO}_{2}$ particle is $6 \mathrm{~nm} \sim 10 \mathrm{~nm}$ with a single size distribution, which corresponds to the nanoparticle. The results in Fig. 1c (inset) indicate that the SAED pattern consists of a ring pattern. This typical polycrystalline ring pattern corresponds to the face-centered cubic polycrystalline structure of $\mathrm{CeO}_{2}$ (Zhang et al. 2007). Fig. 1d shows a single $\mathrm{CeO}_{2}$ nanoparticle, and the $\mathrm{CeO}_{2}$ lattice fringes are clearly visible. The observed lattice spacing (i.e., $0.31 \mathrm{~nm}$ and $0.27 \mathrm{~nm}$ ) are in good agreement with the calculated ones for the (111) and (200) crystal planes of the cubic fluorite phase of $\mathrm{CeO}_{2}$ (Sathish et al. 2011).

\section{$X R D$}

Fig. 2 shows the XRD pattern of the $\mathrm{CeO}_{2} / \mathrm{CNT}$ nanocomposites photocatalyst. As shown in Fig. 2, the main peaks corresponded to the graphene structure of CNTs (002) and the face-centered cubic structure of $\mathrm{CeO}_{2}$ [(111), (200),(220), (311), (222), (400), (331) and (420)], and no impurity peaks were observed. Therefore, no new substances were generated during the preparation. In addition, all of the main peaks of $\mathrm{CeO}_{2}$ were consistent with the standard cubic fluorite structure of $\mathrm{CeO}_{2}$ (PDF 34-0394), indicating that the prepared $\mathrm{CeO}_{2}$ particles have a polycrystalline face-centered cubic structure and exist as $\mathrm{CeO}_{2}$ (Chen et al. 2012), which is in agreement with the analysis of the SAED spectra. The $\mathrm{CeO}_{2}$ particle size calculated using the Scherrer equation (Chen et al. 2011) for the strongest peak (111) was $8.53 \mathrm{~nm}$, which was in good agreement with the results of the particle diameter $(6 \sim 10 \mathrm{~nm})$ obtained from the analysis of the TEM images.

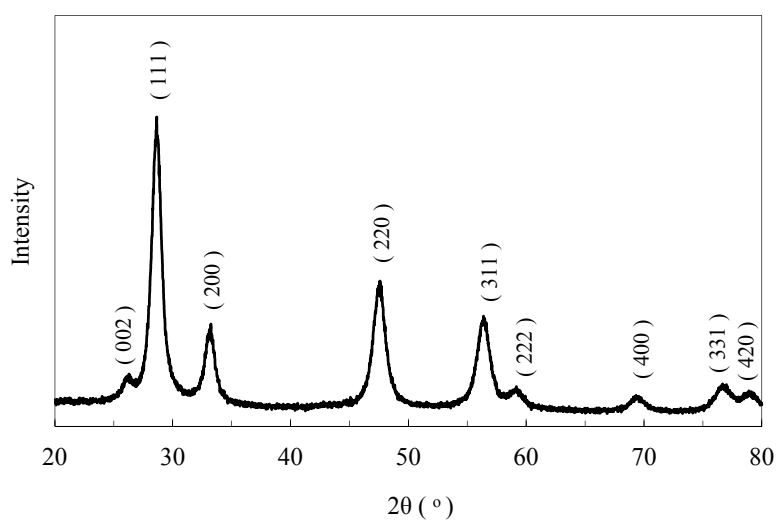

Fig. 2. XRD pattern of the $\mathrm{CeO}_{2} / \mathrm{CNTs}$

$T G A$

Fig. 3 shows the TG curves of the raw CNTs and the nanocomposites photocatalyst precursor CNTs-Ce $(\mathrm{OH})_{3}$. The TG curve of the CNTs (grey line) indicated that the CNTs exhibited good heat resistance during calcination, and almost no loss of quality was observed when the temperature was lower than $500^{\circ} \mathrm{C}$. When the temperature was higher than $550^{\circ} \mathrm{C}$, the weight of the CNTs rapidly decreased, which indicated that the CNTs were being rapidly oxidized. When the temperature reached approximately $580^{\circ} \mathrm{C}$, the CNTs completely disappeared. The TG curve of the nanocomposites photocatalyst precursor CNTs-Ce $(\mathrm{OH})_{3}$ (black line) indicated a weight loss with three steps. The first step occurs at $100 \sim 360^{\circ} \mathrm{C}$ due to the weight loss of precursor dehydration with a mass reduction rate of $3.55 \%$. In the second step from $360^{\circ} \mathrm{C}$ to $520^{\circ} \mathrm{C}$, the precursor weight decreased significantly as the temperature increased, which may be due to dehydrogenation 
of the precursor $\mathrm{Ce}(\mathrm{OH})_{3}$ to form $\mathrm{CeO}_{2}$, and the CNTs were oxidized by the generated $\mathrm{CeO}_{2}$ with a weight loss rate of $43.45 \%$. When the temperature reached and exceeded $520^{\circ} \mathrm{C}$, the sample weight did not vary, which indicated that $\mathrm{Ce}(\mathrm{OH})_{3}$ had been oxidized to $\mathrm{CeO}_{2}$ and the CNTs had been completely decomposed to water and carbon dioxide.

It should be noted that the heat resistance of the CNTs will be reduced greatly due to the existence of $\mathrm{Ce}(\mathrm{OH})_{3}$ and the generation of $\mathrm{CeO}_{2}$ in the calcination process, which could reduce the oxidation temperature of CNTs to $360^{\circ} \mathrm{C}$. The results of previous single factor impact tests obtained by our group (data not shown) confirmed that CNTs in the precursor would be completely decomposed with a calcination temperature of $430^{\circ} \mathrm{C}$ and a holding time of $20 \mathrm{~min}$. Therefore, the calcination temperature and holding time of the precursor should not be too high and too long (Zhang et al. 2007). However, the precursor $\mathrm{Ce}(\mathrm{OH})_{3}$ cannot be entirely prevented from converting to $\mathrm{CeO}_{2}$. In addition, the generated $\mathrm{CeO}_{2}$ cannot form good crystals when the temperature is too low. Therefore, the calcination temperature should be higher than $400^{\circ} \mathrm{C}$ (Zhai et al. 2007), which is contradictory for preparing the nanocomposites photocatalyst. Further investigation is required to determine a balance.

At a calcination temperature of $410^{\circ} \mathrm{C}$, the weight loss rate of the precursors was $8.39 \%$. After subtracting the water loss rate of $3.55 \%$, the CNT loss rate was less than $5 \%$, which is acceptable during the preparation process. In addition, the calcination temperature of $410^{\circ} \mathrm{C}$ is reasonable and feasible based on the above analysis of TEM and XRD.

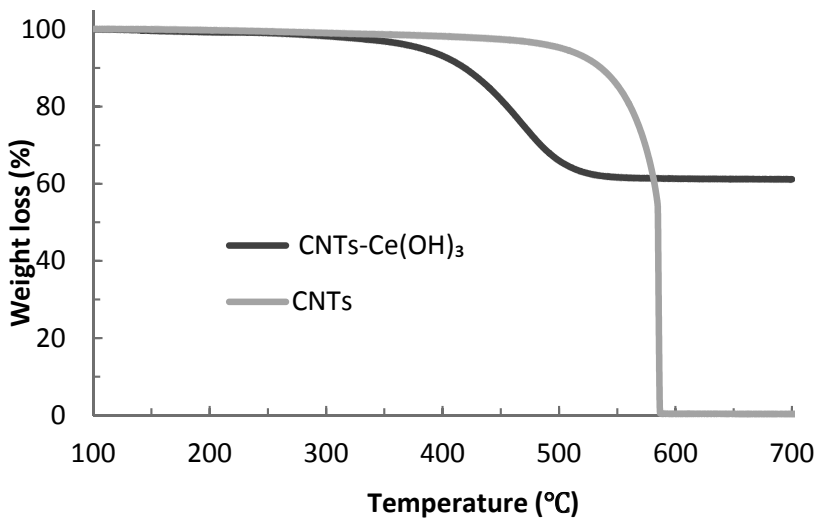

Fig. 3. TG curve of the $\mathrm{CeO}_{2} / \mathrm{CNTs}$ precursor

\section{UV-Vis/ DRS and specific surface area measurements}

Fig. 4 shows the UV-Vis diffuse reflectance spectra of the $\mathrm{CeO}_{2} / \mathrm{CNTs}$ nanocomposites photocatalyst. As shown in Fig. 4, the prepared nanocomposites photocatalyst exhibited a strong ability to absorb light in the ultraviolet region. In addition, the band gap of the product was observed at approximately $450 \mathrm{~nm}$ after making the outside tangent line of the DRS curve. According to the formula $E_{\mathrm{g}}=1240 / \lambda$, the corresponding band gap is $2.76 \mathrm{eV}$, which is slightly lower than that of $2.81 \mathrm{eV}$, $2.95 \mathrm{eV}$ and $3.03 \mathrm{eV}$ reported in the literature (Chen et al. 2012, Feng et al. 2013, Zhao et al.2013) and theoretically results in better efficiency of light utilization. The nanocomposites photocatalyst also exhibited some capacity to absorb light in the visible light region, which implies that the utilization of the xenon lamp simulating solar light to test its photocatalytic property is feasible.

The BET test results of the nanocomposites photocatalyst revealed that the specific surface area of $\mathrm{CeO}_{2} / \mathrm{CNTs}$ was $67.82 \mathrm{~m}^{2} / \mathrm{g}$, which is nearly $70 \%$ higher than the specific surface area of raw CNTs (i.e., $40.00 \mathrm{~m}^{2} / \mathrm{g}$ ) and higher than that of $23.53 \%$ reported in the literature (Peng et al.2005). Therefore, an increase in the specific surface area was achieved, resulting in an increased adsorption capacity of the nanocomposites photocatalyst.

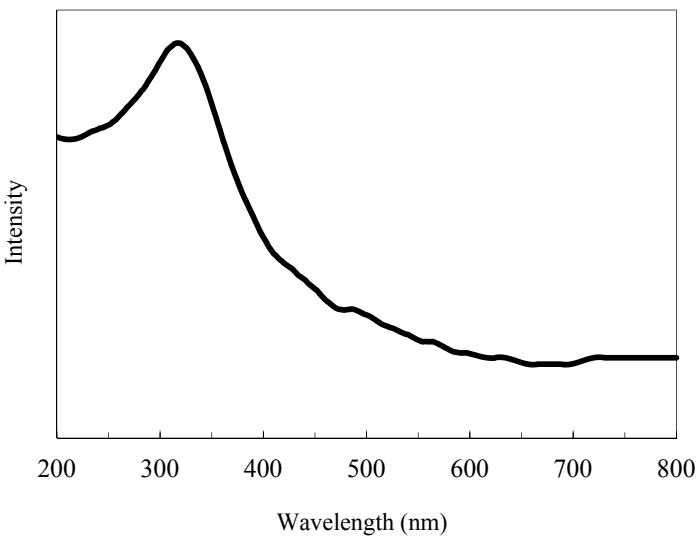

Fig. 4. UV-Vis spectrum of $\mathrm{CeO}_{2} / \mathrm{CNTs}$

\section{XPS}

Fig. 5 shows the X-ray photoelectron spectra of the $\mathrm{CeO}_{2} / \mathrm{CNTs}$ nanocomposites photocatalyst. The wide spectrum (Fig. 5a) of $\mathrm{CeO}_{2} / \mathrm{CNTs}$ only shows the main peaks of the three elements $(\mathrm{Ce}, \mathrm{O}$ and $\mathrm{C})$ without any other elements, indicating that the sample was not contaminated by other elements during preparation and possesses high purity. Based on the XRD analysis, no incompletely reacted precursors were observed in the product. Fig. 5b shows the XPS Ce $3 \mathrm{~d}$ spectrum of $\mathrm{CeO}_{2} / \mathrm{CNTs}$. As shown in Fig. 5b, the peaks at 882, 898, 900.5, 907.3 and $916.5 \mathrm{eV}$ can be attributed to Ce (IV), and the peaks at 882 and $898 \mathrm{eV}$ correspond to the Ce (IV) $3 \mathrm{~d}^{9} 4 \mathrm{f}^{1}$ and $3 \mathrm{~d}^{9} 4 \mathrm{f}^{0}$ final state, respectively. The spin-orbit splitting appears at 900.5, 907.3 and $916.5 \mathrm{eV}$, which corresponds to $3 \mathrm{u}$ peaks of $\mathrm{Ce}(3 \mathrm{~d})_{3 / 2}$, indicating that the $\mathrm{Ce}$ species in the nanocomposites photocatalyst has a IV valence and exists as $\mathrm{CeO}_{2}$ (Mei et al. 2010, Park et al. 1996, Zhang et al. 2010). In addition, the $\mathrm{O} 1 \mathrm{~s}$ spectrum of the prepared $\mathrm{CeO}_{2} / \mathrm{CNTs}$ is shown in Fig. 5c. As shown in Fig. 5c, the $\mathrm{O}$ 1s peak is primarily composed of two peaks centered at 529.1 and $531.4 \mathrm{eV}$, which are due to the lattice oxygen of $\mathrm{CeO}_{2}$ (Rao et al. 2012) and the hydroxyl oxygen on the surface of CNTs or adsorbed oxygen from $\mathrm{CeO}_{2}$ (Lakshminarayanan et al. 2004). In addition, the core level peak, which was located at $529.1 \mathrm{eV}$, indicated the existence of $\mathrm{O}^{2-}$ (Zhang et al. 2007). In addition, the compound has formed a complete $\mathrm{CeO}_{2}$ lattice structure, which is consistent with the XRD and TEM analysis mentioned above. Therefore, the binding energies of $\mathrm{Ce} 3 \mathrm{~d}$ and $\mathrm{O} 1 \mathrm{~s}$ detected by XPS are consistent with those of standard $\mathrm{CeO}_{2}$.

\section{Photocatalytic Performance Testing}

The curves for the variation in the Acid Orange 7 concentration during dark adsorption and photocatalytic degradation in the presence of $\mathrm{CeO}_{2} / \mathrm{CNTs}$, commercial $\mathrm{CeO}_{2}$ and raw CNTs are 
shown in Fig. 6a. As shown in Fig. 6a, the rates of Acid Orange 7 adsorption on the three materials in the dark are fast, and the adsorption-desorption equilibrium was achieved in the first 30 minutes. The adsorption efficiency of Acid Orange 7 on the $\mathrm{CeO}_{2}$ particles without a hole-like or tubular structure was significantly lower than that on CNTs and $\mathrm{CeO}_{2} / \mathrm{CNTs}$. In addition, the total decolorization rate of Acid Orange 7 by the $\mathrm{CeO}_{2} / \mathrm{CNTs}$ nanocomposites photocatalyst was as high as $80.58 \%$, and the optical decolorization rate was $66.58 \%$ after xenon lamp irradiation for $4 \mathrm{~h}$, which is better than that of commercial $\mathrm{CeO}_{2}$ (i.e., $43.13 \%$ ). This result may be due to the adsorption capacity of commercial $\mathrm{CeO}_{2}$ being lower than that of $\mathrm{CeO}_{2} / \mathrm{CNTs}$, which resulted in the Acid Orange 7 molecules being more weakly adsorbed on the surface of commercial $\mathrm{CeO}_{2}$ and affecting its subsequent optical decolorization performance (Chen et al. 2012, Ayanda et al. 2015).

\section{Settling Performance Testing}

Fig. $6 \mathrm{~b}$ shows the sedimentation curves of $\mathrm{CeO}_{2} / \mathrm{CNTs}$, commercial $\mathrm{CeO}_{2}$ and raw CNTs in water. Based on the integral algorithm (Tang et al.2006), the total removal rate of the $\mathrm{CeO}_{2} /$ /CNTs suspended particles at a settling velocity of $1.5 \mathrm{~cm} / \mathrm{min}$ is $59.83 \%$, which is higher than that of CNTs $(16.60 \%)$ and commercial $\mathrm{CeO}_{2}$ (44.40\%), indicating that the $\mathrm{CeO}_{2} / \mathrm{CNTs}$ prepared in this research exhibits good settling performance accelerating its separation from water.
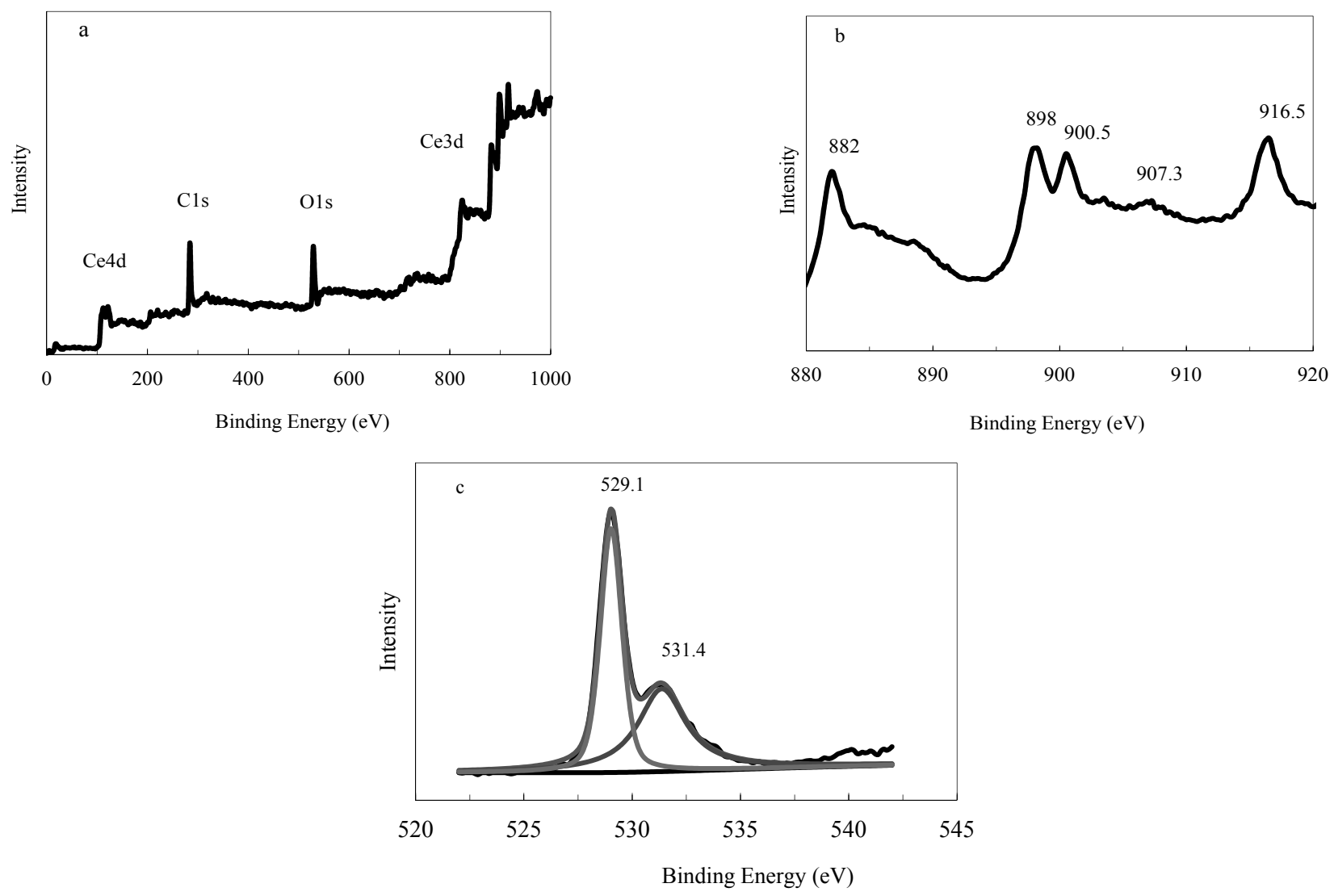

Fig. 5. XPS wide spectrum (a), Ce 3d spectrum (b) and $\mathrm{O}$ 1s spectrum (c) of $\mathrm{CeO}_{2} / \mathrm{CNTs}$

(a)

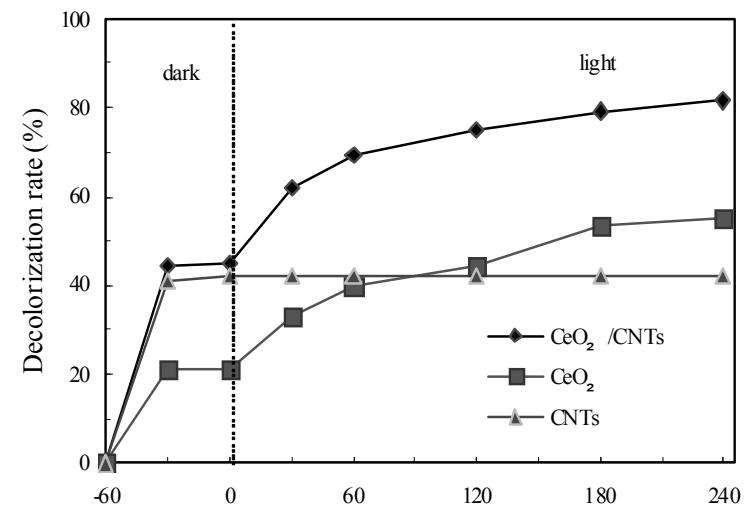

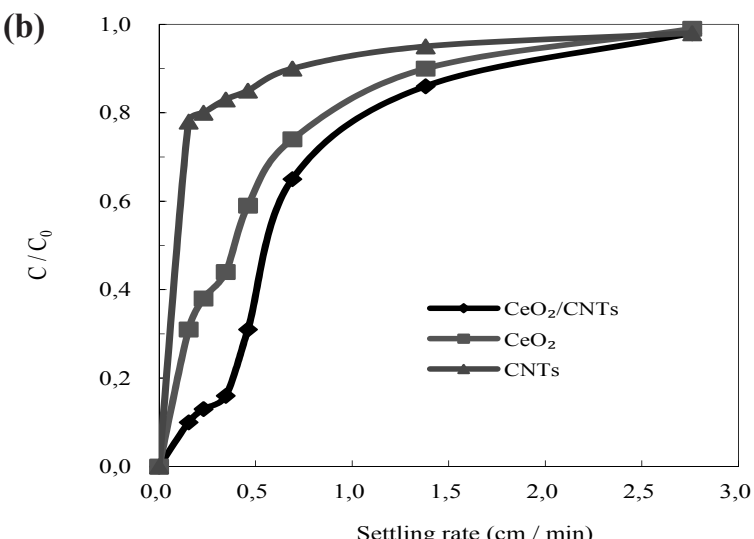

Fig. 6. Changes in the Acid Orange 7 concentration during dark adsorption and photocatalytic degradation (a) and sedimentation curves (b) in the presence of $\mathrm{CeO}_{2} / \mathrm{CNTs}$, commercial $\mathrm{CeO}_{2}$ and raw CNTs 


\section{Conclusions}

$\mathrm{CeO}_{2}$ can be loaded on CNTs uniformly to prepare a $\mathrm{CeO}_{2} /$ /CNTs nanocomposites photocatalyst. The optimized conditions are as follows: stirring reaction time, $4 \mathrm{~h}$; cerium:carbon ratio, $4: 3 ; \mathrm{pH}, 11.5$; calcination temperature, $410^{\circ} \mathrm{C}$; and holding time, $5 \mathrm{~min}$. The prepared nanocomposites photocatalyst has no significant impurities, and the size of the $\mathrm{CeO}_{2}$ loaded on the CNTs is $6 \sim 10 \mathrm{~nm}$. In addition, $\mathrm{CeO}_{2}$ was dispersed on the carbon nanotubes with a good loading effect and a high loading efficiency. The specific surface area of $\mathrm{CeO}_{2} / \mathrm{CNTs}$ is $67.82 \mathrm{~m}^{2} / \mathrm{g}$, which is nearly $70 \%$ higher than that of raw CNTs (i.e., $40.00 \mathrm{~m}^{2} / \mathrm{g}$ ), and $\mathrm{CeO}_{2} / \mathrm{CNTs}$ exhibits a good adsorption capacity. In addition, $\mathrm{CeO}_{2} / \mathrm{CNTs}$ has a strong ability to absorb light in the ultraviolet region and exhibits some capacity to absorb light in the visible light region. The optical decolorization ratio of $\mathrm{CeO}_{2} / \mathrm{CNTs}$ to degrade azo dye Acid Orange $7(40 \mathrm{mg} / \mathrm{L})$ was as high as $66.58 \%$ after xenon lamp irradiation for $4 \mathrm{~h}$, which is better than that of commercial $\mathrm{CeO}_{2}(43.13 \%)$ with an improved settling performance. This result indicates that $\mathrm{CeO}_{2}$ loaded on CNTs can enhance the optical decolorization rate and accelerate the separation of $\mathrm{CeO}_{2} / \mathrm{CNTs}$ and water. Therefore, the prepared $\mathrm{CeO}_{2} / \mathrm{CNTs}$ nanocomposites photocatalytic material exhibits potential for application in the photocatalytic treatment of azo dyes in water.

\section{Acknowledgments}

This work was financially supported by Jiangsu General College Graduate Students Research and Innovation Program, China (CXZZ13_0723).

\section{References}

Ayanda, O.S., Fatoki, O.S., Adekola, F.A., Ximba, B.J., Akinsoji, O.S. \& Petrik, L.F. (2015). Coal fly ash supported $\mathrm{nZnO}$ for the sorption of triphenyltin chloride, Archives of Environmental Protection, 41, pp. 59-71.

Campbell, C.T. \& Peden, C.H.F. (2005). Oxygen vacancies and catalysis on ceria surfaces, Science, 309, pp. 713-714.

Chen, F., Shen, X.X., Wang, Y.C. \& Zhang, J.L. (2012). $\mathrm{CeO}_{2}$ \& $\mathrm{H}_{2} \mathrm{O}_{2}$ system catalytic oxidation mechanism study via a kinetics investigation to the degradation of acid orange7, Appllied Catalysis, B: Environmental, 121-122, pp. 223-229.

Chen, F., Wang, W., Chen, Z.G. \& Wang, T.B. (2012). Biogenic synthesis and catalysis of porous $\mathrm{CeO}_{2}$ hollow microspheres, Journal of Rare Earths, 30, pp. 350-354.

Chen, F.J., Cao, Y.L. \& Jia, D.Z. (2011). Preparation and photocatalytic property of $\mathrm{CeO}_{2}$ lamellar, Appllied Surface Science, 257, pp. 9226-9231.

Esch, F., Fabris, S., Zhou, L., Montini, T., Africh, C., Fornasiero, P., Comelli, G. \& Rosei, R. (2005). Electron localization determines defect formation on ceria substrates, Science, 309, pp. 752-755.

Feng, T., Wang, X.d. \& Feng, G.S. (2013). Synthesis of novel $\mathrm{CeO}_{2}$ microspheres with enhanced solar light photocatalyic properties, Materials Letters, 100, pp. 36-39.

Fu, L., Liu, Z.M., Liu, Y.Q., Han, B.X., Wang, J.Q., Hu, P.A., Cao, L.C. \& Zhu, D.B. (2004). Coating carbon nanotubes with rare earth oxide multiwalled nanotubes, Advanced Materials, 16, pp. 350-352.

Gao, H.J., Zhao, S.Y., Cheng, X.Y., Wang, X.D. \& Zheng, L.Q. (2013). Removal of anionic azo dyes from aqueous solution using magnetic polymer multi-wall carbon nanotube nanocomposite as adsorbent, Chemical Engineering Journal, 223, pp. 84-90.
Guerrero-Ruiz, A. (1994).Carbon monoxide hydrogenation over carbon supported cobalt or ruthenium catalysts. Promoting effects of magnesium, vanadium and cerium oxides, Appllied Catalysis, A: General, 120, pp. 71-83.

Iijima, S. (1991). Helical microtubules of graphitic carbon, Nature, 354, pp. $56-58$.

Ji, P.F., Zhang, J.L., Chen, F. \& Anpo, M. ( 2009). Study of adsorption and degradation of acid orange 7 on the surface of $\mathrm{CeO}_{2}$ under visible light irradiation, Applied Catalysis B: Environmental, 85, pp. 148-154.

Kang, M., Bae, Y.S. \& Lee, C.H. ( 2005). Effect of heat treatment of activated carbon supports on the loading and activity of $\mathrm{Pt}$ catalyst, Carbon, 43, pp. 1512-1516.

Karakoti, A., Singh, S. \& Dowding, J.M. (2010). Redox-active radical scavenging nanomaterials, Chemical Society Reviews, 39 , pp. 4422-4432.

Lakshminarayanan, P.V., Toghiani, H. \& Pittman, Jr, C.U. (2004). Nitric acid oxidation of vapor grown carbon nanofibers, Carbon, 42, pp. 2433-2442.

Long, Z. Q., Ren, L., Zhu, Z.W., Cui, D.L., Zhao, N., Li, M.L., Cui, M.S. \& Huang, X.W. (2006). Synthesis of $\mathrm{LaPO}_{4}$ : Ce, Terbium by Co-Precipitation Method, Journal of Rare Earths, 24, pp. 137-140.

Matsumoto, S. (2004). Recent advances in automobile exhaust catalysts, Catalysis Today, 90, pp. 183-190.

Mei, Y., Yan, J.P. \& Nie, Z.R. (2010). XPS study on the influence of calcination conditions to cerium ion valence, Spestroscopy and Spectral Analysis, 30, pp. 270-273. (in Chinese)

Mishra, A.K., Arockiadoss, T. \& Ramaprabhu, S. (2010). Study of removal of azo dye by functionalized multi walled carbon nanotubes, Chemical Engineering Journal, 162, pp. 1026-1034.

Park, P.W. \& Ledford, J.S. (1996). Effect of crystallinity on the photoreduction of cerium oxide: A study of $\mathrm{CeO}_{2}$ and $\mathrm{Ce} / \mathrm{Al}_{2} \mathrm{O}_{3}$ catalysts, Langmuir, 12, pp. 1794-1799.

Park, S., Vohs, J.M. \& Gorte, R.J. (2000). Direct oxidation of hydrocarbons in a solid-oxide fuel cell, Nature, 404, pp. 265-267.

Peng, X.J., Luan, Z.K., Ding, J., Di, Z.C., Li, Y.H. \& Tian, B.H. (2005). Ceria nanoparticles supported on carbon nanotubes for the removal of arsenate from water, Materials Letters, 59, pp. 399-403.

Planeix, J.M., Coustel, N., Coq, B., Brotons, V., Kumbhar, P.S., Dutartre, R., Geneste, P., Bernier, P. \& Ajayan, P.M. (1994). Application of carbon nanotubes as supports in heterogeneous catalysis, Journal of the American Chemical Society, 116, pp. 7935-7936.

Pouretedal, H.R. \& Kadkhodaie, A. (2010). Synthetic $\mathrm{CeO}_{2}$ nanoparticle catalysis of methylene blue photodegradation: kinetics and mechanism, Chinese Journal of Catalysis, 31, pp. 1328-1334.

Rao, R., Zhang, Q.Y., Liu, H.D., Yang, H.X., Ling, Q., Yang, M., Zhang, A.M. \& Chen, W. (2012). Enhanced catalytic performance of $\mathrm{CeO}_{2}$ confined inside carbon nanotubes for dehydrogenation of ethylbenzene in the presence of $\mathrm{CO}_{2}$, Journal of Molecular Catalysis A: Chemical, 363-364, pp. 283-290.

Rodriguez, J.A., Ma, S., Liu, P., Hrbek, J., Evans, J. \& Pérez, M. (2007). Activity of $\mathrm{CeO}_{x}$ and $\mathrm{TiO}_{x}$ nanoparticles grown on $\mathrm{Au}(111)$ in the water-gas shift reaction, Science, 318, pp. 1757-1760.

Sathish, M., Miyazawa, K. \& Ye, J. (2011). Fullerene nanowhiskers at liquid-liquid interface: A facile template for metal oxide $\left(\mathrm{TiO}_{2}\right.$, $\mathrm{CeO}_{2}$ ) nanofibers and their photocatalytic activity, Materials Chemistry and Physics, 130, pp. 211-217.

Singh, S., Dosani, T., Karakoti, A.S., (2011). A phosphate-dependent shift in redox state of cerium oxide nanoparticles and its effects on catalytic properties, Biomaterials, 32, pp. 6745-6753.

Soria, J., Coronado, J.M. \& Conesa, J.C. (1996). Spectroscopic study of oxygen adsorption on $\mathrm{CeO}_{2} / \gamma-\mathrm{Al}_{2} \mathrm{O}_{3}$ catalyst supports, Journal of the Chemical Society, Faraday Transactions, 92, pp. 1619-1626. 
Tang, Y.B., Chen, F.Y. \& Zhang, Y.F. (2006). Water Pollution Control Engineering, Press of Harbin Institute of Technology, Harbin 2006. (in Chinese)

Trovarelli, A. (2002). Catalysis by Ceria and Related Materials (Catalytic Science Series, vol. 2), Imperial College Press, London 2002.

Trovarelli, A., Deleitenburg, C., Dolcetti, G. \& Lorca, J.L. (1995). $\mathrm{CO}_{2}$ methanation under transient and steady-state conditions over $\mathrm{Rh} / \mathrm{CeO}_{2}$ and $\mathrm{CeO}_{2}$-promoted $\mathrm{Rh} / \mathrm{SiO}_{2}$ : The role of surface and bulk ceria, Journal of Catalysis, 151, pp. 111-124.

Vindigni, F., Manzoli, M., Damin, A., Tabakova, T. \& Zecchina A., (2011). Surface and inner defects in $\mathrm{Au} / \mathrm{CeO}_{2}$ WGS catalysts: Relation between Raman properties, reactivity and morphology, Chemistry - A European Journal, 17, pp. 4356-4361.

Walton, R.I. (2011). Solvothermal synthesis of cerium oxides, Progress in Crystal Growth and Characterization of Materials, 57, pp. 93-108.
Zhai, Y., Zhang, S. \& Pang, H. (2007). Preparation, characterization and photocatalytic activity of $\mathrm{CeO}_{2}$ nanocrystalline using ammonium bicarbonate as precipitant, Materials Letters, 61, pp. $1863-1866$

Zhang, D.S., Fu, H.X., Shi, L.Y., Fang, J.H. \& Li, Q. (2007). Carbon nanotube assisted synthesis of $\mathrm{CeO}_{2}$ nanotubes, Journal of Solid State Chemistry, 180, pp. 654-660.

Zhang, D.S., Mai, H.L., Huang, L. \& Shi, L.Y. ( 2010). Pyridine-thermal synthesis and high catalytic activity of $\mathrm{CeO}_{2} / \mathrm{CuO} / \mathrm{CNT}$ nanocomposites, Applied Surface Science, 256, pp. 6795-6800.

Zhao, P.S., Song, J., Zhou, S.S., Zhu, Y., Jing, L. \& Guo, Z.Y. (2013). Facile 1, 4-dioxane-assisted solvothermal synthesis, optical and electrochemical properties of $\mathrm{CeO}_{2}$ microspheres, Materials Research Bulletin, 48, pp. 4476-4480. 